\title{
Effect of Cross-Linked Enzyme Aggregates Strategy on Characterization of sn-1,3 Extracellular Lipase from Aspergillus Niger GZUF36
}

Ruonan Zhu

Guizhou University

\section{Cuicui Chen}

Guizhou University

\section{Shuqi Xing}

Guizhou University

Yangyang Cai

Guizhou University

Cuiqin $\mathrm{Li}$

Guizhou University

\section{Xuefeng Zeng}

Guizhou University

Laping He ( $\nabla$ helaping@163.com )

Guizhou University https://orcid.org/0000-0002-3523-0872

\section{Research}

Keywords: Sn-1,3 extracellular lipase, Aspergillus niger GZUF36, Cross-linked enzyme aggregates strategy, Characterization

Posted Date: October 6th, 2020

DOI: https://doi.org/10.21203/rs.3.rs-77409/v1

License: (1) (i) This work is licensed under a Creative Commons Attribution 4.0 International License. Read Full License 


\section{Abstract}

Background: A novel Aspergillus. niger strain GZUF36 with two high sn-1,3 position selectivity of lipases, including an intracellular lipase and an extracellular one was selected from oil-rich soil in our previous work. The sn-1,3 extracellular lipase from Aspergillus niger GZUF36 (EXANL1) has important potential applications. However, the structure and properties of this lipase need further study for its better application, the immobilization of enzyme is an effective method to study its structural properties and obtain the best catalytic properties. Cross-linked enzyme aggregates (CLEAs) have been widely used in carrier-free immobilization technologies because of their low cost and fast preparation. To this end, it is necessary to investigate the effect of CLEAs strategy on the characteristics, secondary structure, and positional selectivity of EXANL1 before and after immobilization.

Results: The CLEAs of purified EXANL1 (CLEA-EXANL1) was achieved optimum activity recovery (100.3 $\pm 1.1 \%$ ) with $80 \%$ tert-butanol as the precipitant, a glutaraldehyde (GA) concentration of $30 \mathrm{mM}$, a GA treatment time of $1.5 \mathrm{~h}$, and a centrifugal speed of $6000 \mathrm{~g}$. CLEA-EXANL1 exhibited a broader optimum pH range (4-6) compared with free EXANL1 (6.5). CLEA-EXANL1 presented optimum activity at $40^{\circ} \mathrm{C}$, which was $5{ }^{\circ} \mathrm{C}$ higher than that of free EXANL1. CLEAs strategy decreased the maximum reaction rate and increased the Michaelis-Menten constant of EXANL1 when olive oil emulsion was used as a substrate. Moreover, after 30 days, free EXANL1 lost more than $80.0 \%$ of its activity, whereas CLEAEXANL1 retained more than $90.0 \%$ of its activity. CLEAs strategy improved the tolerance of EXANL1 in polar organic solvents. Fourier transform infrared spectroscopy results showed that the CLEAs technique increased the content of the $\beta$-sheets and $\beta$-turns of EXANL1 and reduced a-helixes and irregular crimp contents. CLEAs strategy did not change the sn-1,3 selectivity of EXANL1.

Conclusion: The effect of CLEAs technology on catalytic properties, structure, selectivity and other characteristics of the EXANL1 was comprehensively explored, which laid a foundation for its subsequent rational transformation and industrial application.

\section{Research Highlights}

1 Sn-1,3 extracellular lipase from A. niger GZUF36 (EXANL1) was further investigated;

2 Cross-linked enzyme aggregates (CLEAs) strategy broadened optimum pH range of EXANL1;

3 CLEAs strategy improved the tolerance of EXANL1 in polar organic solvents;

4 CLEAs strategy did not change the positional selectivity of EXANL1;

5 CLEAs strategy has significantly changed the structural properties of EXANL1.

\section{Background}


Lipase (EC 3.1.1.3), a multipurpose hydrolase [1], hydrolyzes triglycerides to produce diglycerides, fatty acids, glycerol, and monoglycerides and catalyzes various reactions, such as hydrolysis, ester synthesis, acidolysis, and alcoholysis [2]. In general, the conformation of lipase is related to the movement of the lid on the active center of the lipase. When the lid covers the active center, the active center is in a closed state, causing difficulty for substrate molecules to be in proximity to the active center $[3,4]$. On the contrary, when the lid moves, exposing the active center to the solvent, the active center is in an open state, increasing affinity between the enzyme and a hydrophobic substrate, and stabilizing intermediate products in a transition state in the catalytic process [5]. The presence of the lid structure in the enzyme molecules causes lipase to generally exhibit higher catalytic activity in a water-oil interface microenvironment than in a water phase, which is called interfacial activation [6]. Interfacial activation can significantly improve the catalytic activity of lipase and has an important influence on its application in the food industry, precision chemical synthesis, and the pharmaceutical industry [7].

Filamentous fungi, such as Rhizopus, Geotrichum, Rehmannia, Penicillium, and Aspergillus are the preferred sources of lipase production [8]. Filamentous fungi are screened from soils rich in oil, vegetable oil wastes, dairy industry, seeds, and spoiled foods [9]. As a typically lipase from filamentous fungi, Aspergillus niger lipase is widely used in oil processing and production of food additives and detergents because of its selectivity, stability, and wide substrate specificity [6]. A novel $A$. niger strain GZUF36 with two high sn-1,3 position selectivity of lipases, including an intracellular lipase and an extracellular one was selected from oil-rich soil in our previous work [10].

1,3-diacylglycerol (1,3-DAG) is an important functional oil and a drug intermediate [11]. It possesses emulsification, lubrication, antistatic properties due to its unique molecular structure, and is widely used in food processing industry and pharmaceutical industry[12]. Sn-1,3 extracellular lipases are excellent tools for the synthesis of 1,3-DAG [13]. Recently, most of the reports used the commercial lipases to produce 1,3-DAG, resulting in high costs of production. The sn-1,3 extracellular lipase from A. niger GZUF36 (EXANL1) has the potential to synthesis of 1,3-DAG economically, which can effectively reduce the production cost and can be applied in large-scale applications. However, the structure and properties of this lipase need further study for its better application, the immobilization of enzyme is an effective method to study its structural properties and obtain the best catalytic properties [6]. A proper immobilization strategy can improve the stability of the biocatalyst and reduce its cost [14]. Using porous solids may be the most widespread reversible physical immobilization method, which could prevent aggregation, proteolysis, interactions with interfaces [3]. In other cases, the covalent binding to the solid carrier is irreversible and can improve enzyme stability [15]. Furthermore, the activity, selectivity, and specificity of lipase may be tuned during immobilization. However, the cost of support will lead to an increase in the final cost of a biocatalyst, which must be considered in the design of a biocatalyst [16].

In various immobilization methods, some that do not require a support are becoming increasingly popular. Cross-linked enzyme aggregates (CLEAs) $[17,18]$ have been widely used in carrier-free immobilization technologies because of their low cost and fast preparation. The lipase protein is precipitated using precipitants, such as salt, organic solvents, or polymers, and then chemically cross- 
linked by a bifunctional agent or a multifunctional agent [19]. Glutaraldehyde (GA) is a commonly used crosslinking agent, and its cycles are the main structure that may give the reaction of cross-linking [20]. Numerous studies on the CLEAs of lipase, such as the lipases from Thermomyces lanuginosa [21], Geobacillus sp. [22], and Candida antarctica [23] had been conducted. However, the CLEAs of lipase from $A$. niger has been rarely studied. To this end, it is necessary to investigate the effect of CLEAs strategy on the characteristics, secondary structure, and positional selectivity of EXANL1 before and after immobilization. Fourier transform infrared spectroscopy (FTIR) and scanning electron microscopy (SEM) were performed to evaluate the effect of CLEAs technique on the surface morphology and secondary structure of CLEA-EXANL1. The thin layer chromatography (TLC) was used for the positional selectivity analysis of the free lipase and CLEA-EXANL1. This study aimed to provide a reference and theoretical basis for the subsequent rational transformation of EXANL1 and its large-scale industrial application.

\section{Results}

\section{Effects of CLEAs preparation conditions on the activity of CLEA-EXANL1}

The effects of three different types of precipitants, such as salt (ammonium sulfate), organic solvents (tert-butanol and acetone), and polymers (PVA) on the activity of CLEA-EXANL1 were demonstrated. The highest activity recovery was obtained using tert-butanol $(71.6 \pm 0.7 \%)$, followed by that using tertbutanol+acetone $(67.4 \pm 0.8 \%)$, acetone $(64.7 \pm 1 \%)$, saturated ammonium sulfate $(59.3 \pm 1.2 \%)$, PVA $(20.0 \pm 1 \%)(P<0.05)$ (Fig.1a). Therefore, tert-butanol was identified to be the optimal precipitant for the synthesis of CLEA-EXANL1.

Lipase precipitation was conducted with tert-butanol-enzyme solutions with volume ratios ranging from 1-6 ( $\mathrm{v} / \mathrm{v})$. Activity recovery increased when the amount of precipitant was increased to the maximum value and then decreased with the further increase in the amount of the precipitant (Fig. 1b). The highest activity recovery $(84.4 \pm 1 \%)$ was obtained when the volume ratio of tert-butanol-enzyme solution was 4 $(\mathrm{v} / \mathrm{v})$. The activity recovery obtained with this volume ratio was significantly different from that obtained with other volume ratios $(P<0.05)$. Therefore, the optimum volume ratio of tert-butanol-enzyme solution was 4.

The effect of GA concentration on the activity of CLEA-EXANL1 was investigated. The activity recovery initially increased as GA concentration increased (Fig. 1c). The activity recovery at $30 \mathrm{mM}$ concentration reached the maximum value of $90.0 \pm 1.2 \%$ and was higher than that at $10 \mathrm{mM}(52.8 \pm 1.3 \%)$ and $20 \mathrm{mM}$ $(81.7 \pm 0.9 \%)$ concentrations $(P<0.05)$. The activity recovery drastically declined when high $\mathrm{GA}$ concentrations were used. Therefore, $30 \mathrm{mM} \mathrm{GA}$ was selected for the subsequent research.

The effect of GA treatment time on the preparation of CLEAs was assessed (Fig. 1d). The activity recovery increased as GA treatment time was increased to its maximum value $(100.3 \pm 1.1 \%)$ and then decreased with the further prolongation of GA treatment time. The suitable GA treatment time was $1.5 \mathrm{~h}$.

\section{The dependence of optimum temperature and pH of EXANL1 on CLEAs strategy}


The dependence of optimum temperature of EXANL1 on CLEAs strategy was studied within the temperature range of $25^{\circ} \mathrm{C}-55^{\circ} \mathrm{C}$ to assess the optimum temperature of EXANL 1 before and after CLEAs immobilization (Fig. 2a). The maximum activity of free lipase was observed at $35^{\circ} \mathrm{C}$ and that of CLEAEXANL1 was observed at $40{ }^{\circ} \mathrm{C}(P<0.05)$. The optimal temperature of CLEA-EXANL1 shifted slightly to a higher temperature compared with that of free lipase. Compared with that of CLEA-EXANL1, the relative activity of free lipase decreased more significantly with the increase of temperature beyond its optimal value.

The dependence of optimum pH of EXANL1 on CLEAs strategy was evaluated within the range of 4.09.0. The results are displayed in Fig. 2b. CLEA-EXANL1 showed no significant difference in $\mathrm{pH}$ 4.0-6.0 ( $P>0.05$ ). The optimal $\mathrm{pH}$ of the immobilized lipase (4.0-6.0) shifted to the acidic region relative to that of free lipase (6.5). Moreover, CLEA-EXANL1 exhibited good acid resistance under all acidic conditions that the relative activity of CLEAs-EXANL1 exceeded $96.0 \%$ within the $\mathrm{pH}$ range of $4.0-6.0$. By contrast, the relative activity of free lipase at the same $\mathrm{pH}$ value was $38.8 \pm 2.2 \%-68.2 \pm 3.4 \%$. It seems that CLEAs technique broadened the optimum pH range of EXANL1 and improved acid resistance of EXANL1.

\section{The dependence of thermal and pH stability of EXANL1 on CLEAs strategy}

The thermal stability was evaluated for the free lipase and CLEA-EXANL1 at $30^{\circ} \mathrm{C}, 35^{\circ} \mathrm{C}, 40^{\circ} \mathrm{C}, 45^{\circ} \mathrm{C}$, and $50{ }^{\circ} \mathrm{C}$ to investigate the effect of CLEA strategy on thermal stability of EXANL1. According to the data shown in Fig. 3a, the relative activities of free lipase and CLEA-EXANL1 decreased with the prolongation of incubation time over a broad temperature profile. The rate of decrease of the relative activity of free lipase was higher than that of the relative activity of CLEAs.

The effect of CLEAs technique pH stability of CLEA-EXANL1 was studied. The results are presented in Fig. $3 \mathrm{~b}$. The relative activities of free lipase and CLEA-EXANL1 tended to increase initially and then decrease with increasing $\mathrm{pH}$ value. The CLEAs technique improved $\mathrm{pH}$ stability and acid resistance of free EXANL1. The relative activity of CLEA-EXANL1 was $89.7 \pm 3.1 \%$, whereas that of free lipase was only $15.0 \pm 5 \%$ at $\mathrm{pH}$ 4.0. However, the relative activities of free lipase and CLEA-EXANL 1 at pH 8.0 were $26.3 \pm 3 \%$ and $37.5 \pm 3 \%$, respectively. These results indicated that CLEAs technique improved the $\mathrm{pH}$ stability under acid and alkaline conditions. In conclusion, the EXANL1 showed a wider $\mathrm{pH}$ adaptability range than before after CLEAs immobilization.

\section{The dependence of organic solvent tolerance of EXANL1 on CLEAs strategy}

The dependence of organic solvent tolerance of EXANL1 on CLEAs strategy was studied. The order of the relative activity of free EXANL1 in different organic solvents is as follows (Fig. 3c): toluene (100.6 $\pm 2.3 \%$ ) $>$ n-hexane $(94.8 \pm 1 \%)>$ acetone $(85.1 \pm 1.3 \%)>$ dichloromethane $(78.8 \pm 2.3 \%)>$ ethanol $(29.4 \pm 1.6 \%)>$ tetrahydrofuran $(5.0 \pm 1.7 \%)>$ methanol $(4.2 \pm 2 \%)>$ acetic acid $(0 \%)$. As shown in Fig. $3 \mathrm{C}$, the relative activity of CLEA-EXANL1 in different organic solvents is described in the following order: toluene $(104.6 \pm 0.2 \%)>$ dichloromethane $(98.2 \pm 1.5 \%)>$ n-hexane $(89.1 \pm 1.7 \%)>$ ethanol $(87.8 \pm 2.5 \%)>$ acetone $(77.6 \pm 1.7 \%)>$ tetrahydrofuran $(52.5 \pm 1.7 \%)>$ methanol $(38.8 \pm 1.7 \%)>$ acetic acid $(22.9 \pm 3.5 \%)$. The CLEAs 
technique increased the activity of EXANL1 in the aqueous phase after proper treatment with toluene methanol, ethanol, tetrahydrofuran, and acetic acid. The EXANL1 before and after CLEAs immobilization both exhibited considerable tolerance for $\mathrm{n}$-hexane, acetone, and dichloromethane. The activity and stability of CLEA-EXANL1 in organic solvents was higher than that of free lipase indicated that the stability of EXANL1 in different organic solvents was obviously improved via CLEAs strategy. Notably, after proper treatment with toluene, immobilized and free lipase showed increased enzyme activity in the aqueous phase.

\section{Reusability}

The reusability of enzymes is an important issue in conventional industrial applications. CLEA-EXANL1 was cycled eight times to evaluate its reusability. The results are provided in Fig. 3d. The enzyme activity of CLEA-EXANL1 gradually decreased with the prolongation of time. The gradual stabilization of the decline in the enzyme activity of CLEA-EXANL1 since the fifth cycle indicated that CLEA-EXANL1 had improved stability in the later cycle.

\section{The dependence of storage stability of EXANL1 on CLEAs strategy}

The relative activity profiles of free lipase and CLEA-EXANL1 stored at $4{ }^{\circ} \mathrm{C}$ for 30 days were determined to evaluate the effect of CLEAs technique on storage stability of EXANL1(Fig. 3e). The relative activities of CLEA-EXANL1 and free lipase showed a downward trend with the prolongation of storage days. However, the decline rate of CLEA-EXANL1 was significantly lower than that of the free lipase. When the storage time was 12 days, the relative activity of free enzyme was $73.7 \pm 3.7 \%$, whereas that of CLEAEXANL1 remained at approximately $90.0 \%$. After 21 days of storage, the rate of decline of free enzyme activity increased significantly. By contrast, CLEA-EXANL1 showed negligible changes. This result indicated that the storage stability of EXANL1 improved considerably after free EXANL1 was immobilized through CLEAs.

\section{Determination of kinetic parameters}

The effect of CLEAs technique on kinetic parameters of EXANL1 was calculated, and the LineweaverBurk plots are shown in Fig. 3f. In this study, an olive oil emulsion prepared with high stirring rate was used to provide an oil-water interface for promoting the reaction of enzymes and substrates. The result of kinetic parameters of EXANL1 before and after CLEAs immobilization was shown in Table 1. The apparent $K_{\mathrm{m}}$ value of CLEA-EXANL1 $(59.95 \mathrm{~g} / \mathrm{L})$ was higher than that of free lipase $(44.26 \mathrm{~g} / \mathrm{L})$. The affinity between CLEA-EXANL1 and the substrate was lower than that of free lipase. Furthermore, $V_{\max }$ of the CLEA-EXANL1 $(15.74 \mathrm{mmol} / \mathrm{L} / \mathrm{min})$ was slightly lower than that of free lipase $(15.90 \mathrm{mmol} / \mathrm{L} / \mathrm{min})$. These results might be attributed to the conformational change of EXANL1 after precipitation by tertbutanol and cross-linking by GA in the CLEAs immobilization process. The flexibility of EXANL1 was reduced, and rigidity was increased after CLEAs immobilization, thereby limiting contact between the substrate and the active center of the enzyme molecule [24]. Cao et al. [25] reported the increased $K_{\mathrm{m}}$ and dereased $V_{\text {max }}$ of PEl-crosslinked lipase, which was consistent with us. 


\section{Effect of CLEAs strategy on surface morphology of EXANL1}

The effect of CLEAs strategy on surface morphology of EXANL1 was characterized via SEM. The surface structures of CLEA-EXANL1 (Fig. 4b and d) were different from those of free EXANL1 (Fig. 4a and c) under 1000x and 15,000x magnification. The structure of CLEA-EXANL1 was more compact, ordered and homogeneous than that of free EXANL1 under 1000x magnification. The CLEAs technique improved the surface structures of EXANL1 that clusters and numerous holes can be observed on the surfaces of CLEA-EXANL1 under 15,000× magnification. Free EXANL1 exhibited morphological features of uneven sizes and shapes under 1000x magnification. The structure of free EXANL1 appeared loose under 15,000x magnification. Moreover, the particle size of CLEA-EXANL1 was approximately $50 \mu \mathrm{m}$. The size range of CLEA grains is $0.1-200 \mu \mathrm{m}[26,27]$, and CLEA within the size of 5-50 $\mu \mathrm{m}$ are conducive for batch operations [28]. Therefore, the particle size of CLEA-EXANL1 is consistent with the general particle size range of general CLEAs.

\section{Effect of CLEAs strategy on secondary structure of EXANL1}

In this study, FTIR was performed to study the effect of CLEAs technique on secondary structure of EXANL1. The classification of each peak was confirmed by referring to the wavelength range of the ahelix (1645-1662 cm $\left.\mathrm{cm}^{-1}\right), \beta$-fold (1613-1640 and 1682-1689 $\left.\mathrm{cm}^{-1}\right), \beta$-turn angle $\left(1662-1682 \mathrm{~cm}^{-1}\right)$, and irregular crimp $\left(1640-1645 \mathrm{~cm}^{-1}\right)[29,30]$. The relative content of each secondary structure was obtained by calculating the relative area of each peak (Table 1). The fitting curve of the FTIR peaks of free lipase and CLEA-EXANL1 amide I band and the relative content composition of their secondary protein structures are shown in Fig. 5a and b. The secondary structure of the lipase significantly changed after the immobilization of CLEAs. The contents of $\beta$-sheets and $\beta$-turn angles were increased by $27.2 \%$ and $5.98 \%$, respectively. The contents of a-helixes and irregular crimps were reduced by $3.97 \%$ and $29.21 \%$, respectively. The $\beta$-turn also showed a slight increase, and the hydrogen bond in the $\beta$-turn was unstable because it was formed by the carbonyl group of the first amino acid residue and the amino group of the fourth amino acid residue. However, the decrement in the a-helix with the increment in the $\beta$-fold and $\beta$ turn angle might be caused by the dehydrating effect exerted on the enzyme by the organic solvents used as precipitants on the enzyme.

\section{Effect of CLEAs strategy on the positional selectivity of EXANL1}

As shown in the TLC spectrum (Fig. 6), the main products obtained from the hydrolysis of trioleins by free EXANL1 and CLEAs-EXANL1 were 1,2-DAG and oleic acid. This result indicated that the free lipase and CLEA-EXANL1 presented sn-1,3 positional selectivity. Moreover, the positional selectivity of free lipase and CLEA-EXANL1 was similar to that of PPL. Nevertheless, the production of a small amount of 1,3-DAG along with 1,2-diglyceride (1,2-DAG) in the hydrolyzed products of PPL indicated that the sn-1,3 positional selectivity of free lipase and CLEA-EXANL1 was higher than that of PPL. Therefore, CLEAs strategy did not change the sn-1,3 selectivity of EXANL1. 


\section{Discussion}

In this study, a purified EXANL1 by combining acetone precipitation and reverse micellar extraction [1] was applied to synthesis CLEAs. The structure and properties of EXANL1 need further study for its better application, the immobilization of enzyme is an effective method to study its structural properties and obtain the best catalytic properties. The optimum temperature and $\mathrm{pH}$, stability of temperature and $\mathrm{pH}$, organic solvent tolerance, operating stability, and storage stability of free EXANL1 and CLEA-EXANL1 were evaluated and compared. CLEAs strategy improved the thermostability of the EXANL1. It is attributed to the structure of lipase changed after cross-linking, the conformational flexibility and tension of lipase decreased, whereas the degree of molecular rigidity increased [31]. An increasing number of intermolecular and intramolecular covalent bonds of CLEA-EXANL1 reflect the weak influence of temperature on its activity and thus improved the thermostability of lipase. CLEA-EXANL1 exhibited good acid resistance under all acidic conditions that the relative activity of CLEAs-EXANL1 exceeded $96.0 \%$ within the $\mathrm{pH}$ range of 4.0-6.0. The changes in optimum $\mathrm{pH}$ of EXANL1 after CLEAs immobilization may be explained that the corresponding changes in the side chain ionization of acidic and basic amino acids in the microenvironment around the active site caused by the formation of Schiff bases between basic residues of enzyme and GA during cross-linking [32].

Accordingly, the CLEAs technique could improve the thermal stability of EXANL1 which correlated with reducing the thermal vibration of the inner groups of molecules and hindering the thermal extensibility of enzyme molecules. CLEAs technique increased the activity of EXANL1 in the aqueous phase after proper treatment with toluene methanol, ethanol, tetrahydrofuran, and acetic acid indicated that the organic solvent tolerance of the EXANL1 had changed during the formation of CLEAs through two mechanisms. First, enzyme cross-linking increased the rigidity of the enzyme molecule [33] and reduced the threedimensional structure of the protein in organic solvents, thereby protecting the active site of the enzyme. Second, the change in hydrophobic/hydrophilic residues on the surface of the enzyme molecule during enzyme fixation $[34,35]$ may have hindered hydrophilic solvents, such as ethanol, from entering the interior of the enzyme molecule.

Lipase has an oil-water interface affinity and can catalyze the hydrolysis of insoluble lipids at a high rate on the oil-water interface, which is called interfacial activation $[3,36]$. Using an insoluble substrate such as olive oil, vegetable oil, and triolein, which form drops, could provide oil-water interface. Thus, the substrate concentration here is actually the surface olive oil concentration of the emulsified droplets. Given that interfacial activation is a typical catalytic property of lipase, it is suitable to measure the $K_{\mathrm{m}}$ with emulsion micro drop. A saturating substrate concentration is reached at the oil-water interface when lipase molecules are adsorbed at all droplet surface [37].

According to the results of the enzymatic properties and structures of free EXANL1 and CLEA-EXANL1, cross-linking can be inferred to change the structure or properties of enzyme molecules. However, this change only resulted in differences in some enzymatic properties of EXANL 1 , and did not affect the positional selectivity of this lipase during hydrolysis. 


\section{Conclusion}

The CLEAs technology helped EXANL1 obtain the best catalytic properties and improved the stability of EXANL1. The CLEA-EXANL1 displayed a broader optimum $\mathrm{pH}$ range and better thermostability, storage stability, and reusability than that of free lipase. CLEA-EXANL1 maintained $54.5 \%$ relative activity after four times of recycling. The stability of CLEA-EXANL1 in different organic solvents was higher than that of free lipase. Notably, the proper treatment of toluene could increase the enzyme activity of free and immobilized lipase in water solution. The FTIR and SEM characterization results for CLEA-EXANL1 showed that the structure of lipase has changed after CLEAs immobilization. TLC analysis revealed that CLEA-EXANL1 retained the sn-1,3 selectivity of free EXANL1 in hydrolysis. The effect of CLEAs technology on catalytic properties, structure, selectivity and other characteristics of the EXANL1 was comprehensively explored, which laid a foundation for its subsequent rational transformation and industrial application.

\section{Materials And Methods}

\section{Strains and chemicals}

A. niger GZUF36 was isolated in our laboratory and deposited at the China Center for Type Culture Collection (CCTCC) under the CCTCC Preservation No. M2012538. Polyvinyl alcohol (PVA) and tertbutanol were purchased from Tianjin Kemiou Chemical Reagent Co. (Tianjin, China). GA (50\%) and oleic acid were purchased from Chengdu Jinshan Chemical Reagent Co. (Chengdu, Sichuan, China). Anhydrous ethanol was purchased from Tianjin Fuyu Fine Chemical Reagent Co. (Tianjin, China). Acetone was purchased from Chuandong Chemical Group Co. (Chongqing, China). TLC-grade porcine pancreatic lipase (PPL, $1000 \mathrm{U} / \mathrm{g}$ ), triolein, 1,3-diglycedide, and 1,2-diglycedide were procured from SigmaAldrich Co. (USA). Olive oil was acquired from Sinopharm Chemical Reagent Co. (Shanghai, China). All other chemical reagents were of analytical grade and commercially available.

\section{Production of EXANL1}

Two-ring spores of $A$. niger GZUF36 were inoculated into the fermentation medium and incubated for 60 $\mathrm{h}$ at $30^{\circ} \mathrm{C}$ at $180 \mathrm{rpm}$. Then the mycelium was filtered and the fermentation broth was centrifuged at $4000 \mathrm{~g}$ and $4^{\circ} \mathrm{C}$ for $15 \mathrm{~min}$ to obtain the crude EXANL1 solution.

\section{Purification of EXANL1}

The crude EXANL1 was purified by reverse micelle extraction combined with acetone precipitation. 250 $\mathrm{mL}$ of acetone was added into $100 \mathrm{~mL}$ crude enzyme solution at $-18{ }^{\circ} \mathrm{C}$ for $3 \mathrm{~h}$. The mixture was then centrifuged at $6000 \mathrm{~g}$ and $4{ }^{\circ} \mathrm{C}$ for $15 \mathrm{~min}$. The forward extraction and backward extraction were referred to our previous work [1].

\section{Synthesis of CLEA-EXANL1}


CLEA-EXANL1 was synthesized in accordance with the method described by Rehman et al. [38] with some modifications. CLEA-EXANL1 was prepared by adding some amounts of precipitants and crosslinker GA into $10 \mathrm{~mL}$ of purified enzyme solution. The mixture was agitated at $200 \mathrm{rpm}$ and $25^{\circ} \mathrm{C}$ for some time and then centrifuged at $4{ }^{\circ} \mathrm{C}$ for $15 \mathrm{~min}$ at $6000 \mathrm{~g}$ to collect the aggregates. And the effect of precipitants (acetone, saturated ammonium sulfate, tert-butanol, PVA, and a mixture of tert-butanol and acetone), volumes (one-, two-, three-, four-, five-, and six-folds) of precipitants, quantities of the crosslinker $\mathrm{GA}(10-60 \mathrm{mM})$ and cross-linking time $(0.5,1,1.5,2,2.5,3,3.5,4)$ on the activity of CLEA-EXANL1 were investigated.

The recovered CLEA-EXANL1 was thoroughly washed with the relevant solvents until enzyme activity in the supernatant was undetectable. CLEA-EXANL1 was then stored in $50 \mathrm{mM}$ PBS buffer at $4{ }^{\circ} \mathrm{C}$ for further use.

\section{Assay of EXANL1 activity}

The activity of free EXANL 1 and CLEAs was measured via alkali titration. The reaction mixtures consisted of $4 \mathrm{~mL}$ of olive oil emulsification, $5 \mathrm{~mL}$ of $25 \mathrm{mM}$ sodium phosphate buffer (pH 6.4), and $1 \mathrm{~mL}$ of enzyme solution. The reaction mixtures were placed in $50 \mathrm{~mL}$ Erlenmeyer flasks with a glass stopper and incubated at $34^{\circ} \mathrm{C}$ for 15 min with constant agitation. The reaction was terminated with $15 \mathrm{~mL}$ of $95 \%$ ethanol. One unit of lipase activity was defined as the amount of enzyme releasing $1 \mu \mathrm{mol}$ of fatty acid per minute. Eq. (1) was used to calculate activity recovery:

Activity recovery $(\%)=\frac{\text { Total activity }(\mathrm{U} / \mathrm{g}) \text { of CLEA-EXANL1 }}{\text { Total activity }(\mathrm{U} / \mathrm{g}) \text { of pure EXANL1 used for CLEA preparation }} \times 100$

\section{Optimum temperature and pH of EXANL1 and CLEA-EXANL1}

The effect of CLEAs strategy on optimum temperature of EXANL1 was studied by measuring the activity of free EXANL 1 and CLEAs for $15 \mathrm{~min}$ at $25-55^{\circ} \mathrm{C}$. Enzyme activity was measured through the alkali titration method, as described in Section 2.5. The highest enzyme activity of free and CLEAs of EXANL1 within these temperature ranges was defined as $100 \%$. The effect of CLEAs strategy on optimum $\mathrm{pH}$ of EXANL1 was determined by performing the activity assay under the $\mathrm{pH}$ range of 4.0-9.0. Furthermore, $0.1 \mathrm{M}$ citrate buffer was used for $\mathrm{pH} 4.0-5.0,0.2 \mathrm{M}$ phosphate buffer was used for $\mathrm{pH}$ 5.0-7.0, and 0.2 M boric acid buffer was used for $\mathrm{pH}$ 8.0-9.0. The activities of free and CLEAs of EXANL1 were determined via the method described in section 2.5. Enzyme activity was defined as described above.

\section{Thermal and pH stability of EXANL1 and CLEA-EXANL1}

Free EXANL 1 and CLEA-EXANL1 were incubated at $30^{\circ} \mathrm{C}, 35^{\circ} \mathrm{C}, 40^{\circ} \mathrm{C}, 45^{\circ} \mathrm{C}$ and $50{ }^{\circ} \mathrm{C}$ for $10 \mathrm{~h}$ to investigate the effect of CLEAs technique on the thermal stability of EXANL1. The relative activities of free EXANL1 and CLEA-EXANL1 without heat treatment were defined as $100 \%$, and the relative activities of free lipase and CLEA-EXANL1 at different temperature values $\left(30{ }^{\circ} \mathrm{C}-50^{\circ} \mathrm{C}\right)$ were determined via the 
method described in Section 2.5. The effect of CLEAs technique on the pH stability of EXANL1 was estimated by incubating free lipase and CLEA-EXANL1 at different $\mathrm{pH}$ values (4.0-8.0). After vacuum freeze drying, free EXANL1 and CLEA-EXANL1 were added to buffer solutions with $\mathrm{pH}$ values of 4.0, 4.5, 5.0, 5.5, 6.0, 6.5, 7.0, 7.5, and 8.0 for $2 \mathrm{~h}$. The activities of untreated free EXANL1 and CLEA-EXANL1 were defined as $100 \%$.

\section{Stability of EXANL1 andCLEA-EXANL1 in organic solvents}

To study the effect of CLEAs strategy on the organic solvent stability of EXANL1, free EXANL1 and CLEAEXANL1 in selected organic solvents were treated as follows. Free EXANL1 and CLEA-EXANL1 were weighed after vacuum freeze-drying in a test tube containing $10 \mathrm{~mL}$ of organic solvent, such as methanol, acetone, ethanol, dichloromethane, tetrahydrofuran, toluene, $n$-hexane, and acetic acid, at room temperature for $20 \mathrm{~h}$. The above mixtures were centrifuged at $4000 \mathrm{~g}$ and $4{ }^{\circ} \mathrm{C}$ for $15 \mathrm{~min}$. Then, free EXANL1 and CLEA-EXANL1 treated with organic solvents were suspended in a sodium phosphate buffer solution ( $\mathrm{pH}$ 7.0). The activities of free EXANL1 and CLEA-EXANL1 were determined in accordance with the method presented in Section 2.5, and the definition of enzyme activity was the same as that mentioned in Section 2.6.2.

\section{Operational stability}

A certain amount of vacuum freeze-dried CLEA-EXANL1 was reacted with an olive oil emulsion in a constant-temperature water bath oscillator at $34^{\circ} \mathrm{C}$ and $180 \mathrm{rpm}$ for $15 \mathrm{~min}$. After a cycle of the hydrolytic activity assay, insoluble CLEA-EXANL1 was separated from the reaction medium by centrifugation at $6000 \mathrm{~g}$ for $15 \mathrm{~min}$. Then, CLEA-EXANL1 was removed and placed in the next batch of fresh substrates to continue the reaction. The relative activity of CLEA-EXANL1 in the first cycle was defined as $100 \%$ and measured in accordance with the method described in Section 2.5 .

\section{Storage stability of EXANL1 and CLEA-EXANL1}

Free EXANL1 and CLEA-EXANL1 were stored at $4{ }^{\circ} \mathrm{C}$ for one month to investigate the effect of CLEAs strategy on storage stability of EXANL1, and relative activities of free EXANL1 and CLEA-EXANL1 was measured once every 3 days in accordance with the method described in Section 2.5. The activities of free EXANL1 and CLEA-EXANL1 before storage were defined as $100 \%$. The stability of relative activity at different storage times was studied to ensure permanent dissolution and the retention of preorganized superstructure to maintain catalytic activity.

\section{Kinetic parameters of EXANL1 and CLEA-EXANL1}

Olive oil was emulsified with $4 \%(\mathrm{w} / \mathrm{v})$ polyvinyl alcohol solution at a ratio of $1: 3(\mathrm{v} / \mathrm{v})$ under a high stirring rate. Approximately $4 \mathrm{~mL}$ of olive oil emulsion (30-120 g/L), $5 \mathrm{~mL}$ of $25 \mathrm{mM}$ PBS buffer (pH 6.4), and $1 \mathrm{~mL}$ of EXANL1 or CLEA-EXANL1 were allowed to react at $34{ }^{\circ} \mathrm{C}$ for $15 \mathrm{~min}$ with constant agitation to determine the effect of CLEAs strategy on the kinetic parameters of EXANL1. The apparent kinetic 
parameters, namely, Michaelis-Menten constant $\left(K_{\mathrm{m}}\right)$ and maximum reaction rate $\left(V_{\text {max }}\right)$, were calculated using the Lineweaver-Burk method and Michaelis-Menten model, as shown in Eq. (2):

$$
\frac{1}{v}=\frac{K_{\mathrm{m}}}{V_{\max }} \times \frac{1}{[\mathrm{~S}]}+\frac{1}{V_{\max }}
$$

where $v$ is the reaction rate, $[S](\mathrm{g} / \mathrm{L})$ is the olive oil concentration of the surface of drops, $V_{\max }$ $(\mathrm{mmol} / \mathrm{L} / \mathrm{min})$ is the maximum reaction rate at saturating substrate concentration and $K_{\mathrm{m}}(\mathrm{g} / \mathrm{L})$ is the Michaelis-Menten constant.

\section{Surface morphology analysis}

Free EXANL1 and CLEA-EXANL1 were ground into powder after vacuum freeze-drying and evenly sprinkled on the SEM sample table. Then, the surface of the sample was sprayed with gold under vacuum. Subsequently, the surface morphology and particle size of the free EXANL1 and CLEA-EXANL1 were characterized via SEM (S-3400N, Hitachi, Japan).

\section{FTIR analysis}

Changes in the secondary structure of EXANL1 through CLEAs immobilization were analyzed via FTIR. Vacuum freeze-dried free EXANL1 and CLEA-EXANL1 were mixed with $\mathrm{KBr}$ at room temperature, ground and pressed into transparent sheets. A Nicolet is 5 infrared spectrometer (Nicolet is5, Thermo fisher, America) was used to scan free EXANL1 and CLEA-EXANL1 within the wave number range of 400-4000 $\mathrm{cm}^{-1}$. Absorbance data were converted, and spectra were processed by Peakfit 4.12. The amide I spectrum with a wavelength range of 1600-1700 cm-1 was selected for baseline correction, and the Peakfit 4.12 software was used for peak segmentation fitting to obtain six subpeaks.

\section{Positional selectivity analysis}

Hydrolysis was conducted as described by Yamamoto et al. [39] with some modifications. $0.1 \mathrm{~mL}$ of triolein and $1 \mathrm{~mL}$ of enzyme (free EXANL1, CLEA-EXANL1 and porcine pancreas lipase [PPL]) were placed in $50 \mathrm{~mL}$ Erlenmeyer flasks with a glass-stopper and incubated at $30^{\circ} \mathrm{C}$ for $15 \mathrm{~min}$ at $180 \mathrm{rpm}$ for hydrolysate extraction. Then, $20 \mathrm{~mL}$ of $\mathrm{n}$-hexane was added to the extracted hydrolysate for $30 \mathrm{~min}$. The upper phase solution was used for TLC analysis.

\section{Statistical analysis}

All analytical experiments were performed in triplicate, and the results were reported as the mean values of replicates along with standard deviation. Collected data were subjected to analysis of variance by using the Statistical Analysis System software, where $P<0.05$ was considered statistically significant.

\section{Abbreviations}


CLEAs: Cross-linked enzyme aggregates

EXANL1: The sn-1,3 extracellular lipase from Aspergillus niger GZUF36

1,3-DAG: 1,3-diacylglycerol

GA: Glutaraldehyde

FTIR: Fourier transform infrared spectroscopy

SEM: Scanning electron microscopy

TLC: Thin layer chromatography

PVA: Polyvinyl alcohol

\section{Declaration}

Ethics approval and consent to participate

Not applicable.

\section{Consent for publication}

Not applicable.

\section{Availability of data and materials}

The datasets used and/or analysed during the current study are available from the corresponding author on reasonable request.

\section{Competing interests}

The authors declare that they have no competing interests.

\section{Funding}

This work was financially supported by the Key Agricultural Project of Guizhou Province (QKHZC[2016]2580 and QKHZC-[2019]2382), the National Natural Science Foundation of China (31870002 and 31660010), the Guizhou University Introduced Talent Project (GZU RGHZ (2019)33) and the Qiankehe talents project ([2018]5781 and [2017]5788-11).

\section{Authors' contributions}

RZ performed the experiments. CC wrote the original manuscript. SX performed the data analysis. YC checked the original data. $\mathrm{CL}$ reviewed the manuscript. XZ contributed analysis tools for structure. $\mathrm{LH}$ 
conceived and designed the experiments. All authors read and approved the final manuscript.

\section{Acknowledgements}

Not applicable.

\section{References}

1. Chen CC, Tian H, Xing SQ, Li CQ, Zeng XF, He LP. Influence of different parameters on reverse micelle extraction combined with acetone precipitation to purify sn-1,3 extracellular lipase from Aspergillus niger GZUF36. J Food Sci Technol. 2019;56:2899-2908.

2. Aljawish A, Heuson E, Bigan M, Froidevaux R. Lipase catalyzed esterification of formic acid in solvent and solvent-free systems. Biocatal Agric Biotechnol. 2019;20:101221.

3. Garcia-Galan C, Berenguer-Murcia Á, Fernandez-Lafuente R, Rodrigues RC. Potential of different enzyme immobilization strategies to improve enzyme performance. Adv Synth Catal. 2011;353:28852904.

4. Rehm S, Trodler P, Pleiss J. Solvent-induced lid opening in lipases: a molecular dynamics study. Protein Sci. 2010;19:2122-2130.

5. Tejo BA, Salleh AB, Pleiss J. Structure and dynamics of Candida rugosa lipase: the role of organic solvent. J Mol Model. 2004;10:358-366.

6. Contesini FJ, Lopes DB, Macedo GA, Nascimento MdG, Carvalho PdO. Aspergillus sp. lipase: potential biocatalyst for industrial use. J Mol Catal B: Enzym. 2010;67:163-171.

7. Zhang Y, Sun WH, Elfeky NM, Wang YP, Zhao DY, Zhou H, Wang JY, Bao YM. Self-assembly of lipase hybrid nanoflowers with bifunctional $\mathrm{Ca} 2+$ for improved activity and stability. Enzyme Microb Technol. 2020;132:8.

8. Singh AK, Mukhopadhyay M. Overview of Fungal Lipase: A Review. Appl Biochem Biotechnol. 2011;166:486-520.

9. CG. AE, Cavalcanti-Oliveira ED, Freire DMG. Current status and new developments of biodiesel production using fungal lipases. Fuel. 2015;159:52-67.

10. Li CQ, Zhang FH, Gao ZX, He LP, Zeng XF, Zhu QJ, Yu L. Effects of organic solvent, water activity, and salt hydrate pair on the sn-1,3 selectivity and activity of whole-cell lipase from Aspergillus niger GZUF36. Appl Microbiol Biotechnol. 2017;102:225-235.

11. Prabhavathi Devi BLA, Gangadhar KN, Prasad RBN, Sugasini D, Rao YPC, Lokesh BR. Nutritionally enriched 1,3-diacylglycerol-rich oil: low calorie fat with hypolipidemic effects in rats. Food Chem. 2018;248:210-216.

12. Guo Z, Sun Y. Solvent-free production of 1,3-diglyceride of CLA: strategy consideration and protocol design. Food Chem. 2007;100:1076-1084.

13. Zhao JF, Tao W, Lin JP, Yang LR, Wu MB. Preparation of high-purity 1,3-diacylglycerol using performance-enhanced lipase immobilized on nanosized magnetite particles. Biotechnol Bioproc E. 
2019;24:326-336.

14. Hassan ME, Yang Q, Xiao Z, Liu L, Wang N, Cui X, Yang L. Impact of immobilization technology in industrial and pharmaceutical applications. 3 Biotech. 2019;9:440.

15. Liu DM, Chen J, Shi YP. Advances on methods and easy separated support materials for enzymes immobilization. TrAC, Trends Anal Chem. 2018;102:332-342.

16. Rodrigues RC, Virgen-Ortíz JJ, dos Santos JCS, Berenguer-Murcia Á, Alcantara AR, Barbosa O, Ortiz C, Fernandez-Lafuente R. Immobilization of lipases on hydrophobic supports: immobilization mechanism, advantages, problems, and solutions. Biotechnol Adv. 2019;37:746-770.

17. Velasco-Lozano S, López-Gallego F, Mateos-Díaz JC, Favela-Torres E. Cross-linked enzyme aggregates (CLEA) in enzyme improvement - a review. Biocatalysis. 2016;1:166-177.

18. Sheldon RA, Schoevaart R, Van Langen LM. Cross-linked enzyme aggregates (CLEAs): a novel and versatile method for enzyme immobilization (a review). Biocatal Biotransform. 2009;23:141-147.

19. Ramos MD, Miranda LP, Fernandez-Lafuente R, Kopp W, Tardioli PW. Improving the yields and reaction rate in the ethanolysis of soybean oil by using mixtures of lipase CLEAs. Molecules. 2019;24.

20. Barbosa O, Ortiz C, Berenguer-Murcia Á, Torres R, Rodrigues RC, Fernandez-Lafuente R. Glutaraldehyde in bio-catalysts design: a useful crosslinker and a versatile tool in enzyme immobilization. RSC Adv. 2014;4:1583-1600.

21. Guauque Torres MP, Foresti ML, Ferreira ML. Effect of different parameters on the hydrolytic activity of cross-linked enzyme aggregates (CLEAs) of lipase from Thermomyces lanuginosa. Biochemical Engineering Journal. 2013;72:18-23.

22. Jamwal S, Dharela R, Gupta R, Ahn JH, Chauhan GS. Synthesis of crosslinked lipase aggregates and their use in the synthesis of aspirin. Chem Eng Res Des. 2015;97:159-164.

23. Wang HH, Liu WJ, Gao LY, Lu YF, Chen EX, Xu YC, Liu HL. Synthesis of n-butyl acetate via reactive distillation column using Candida antarctica lipase as catalyst. Bioproc Biosyst Eng. 2019.

24. Klibanov AM. Why are enzymes less active in organic solvents than in water? Trends Biotechnol. 1997;15:97-101.

25. Cao YP, Xia YP, Gu XF, Han L, Chen Q, Zhi GY, Zhang DH. PEl-crosslinked lipase on the surface of magnetic microspheres and its characteristics. Colloids Surf B Biointerfaces. 2020;189:110874.

26. Yang XE, Zheng P, Ni Y, Sun ZH. Highly efficient biosynthesis of sucrose-6-acetate with cross-linked aggregates of Lipozyme TL 100 L. J Biotechnol. 2012;161:27-33.

27. Mukherjee J, Majumder AB, Gupta MN. Adding an appropriate amino acid during crosslinking results in more stable crosslinked enzyme aggregates. Anal Biochem. 2016;507:27-32.

28. Nair AR, Chellapan G. Improving operational stability of thermostable Pythium myriotylum secretory serine protease by preparation of cross-linked enzyme aggregates (CLEAs). Prep Biochem Biotech. 2019;50:107-115. 
29. Yu PQ, Mckinnon JJ, Christensen CR, Christensen DA. Using synchrotron-based FTIR microspectroscopy to reveal chemical features of feather protein secondary structure: comparison with other feed protein sources. J Agr Food Chem. 2004;52:7353-7361.

30. Özacar M, Mehde AA, Mehdi WA, Özacar ZZ, Severgün O. The novel multi cross-linked enzyme aggregates of protease, lipase, and catalase production from the sunflower seeds, characterization and application. Colloids Surf B Biointerfaces. 2019;173:58-68.

31. Razib MSM, Rahman RNZRA, Shariff FM, Ali MSM. Biochemical and structural characterization of cross-linked enzyme aggregates (CLEAs) of organic solvent tolerant protease. Catalysts. 2020;10:216.

32. Lai JQ, Hu ZL, Sheldon RA, Yang Z. Catalytic performance of cross-linked enzyme aggregates of Penicillium expansum lipase and their use as catalyst for biodiesel production. Process Biochem. 2012;47:2058-2063.

33. Kumar A, Wu GB, Liu ZD. Synthesis and characterization of cross linked enzyme aggregates of serine hydroxyl methyltransferase from Idiomerina leihiensis. Int J Biol Macromol. 2018;117:683-690.

34. Bian H, Cao M, Wen H, Tan Z, Jia S, Cui J. Biodegradation of polyvinyl alcohol using cross-linked enzyme aggregates of degrading enzymes from Bacillus niacini. International Journal of Biological Macromolecules. 2019;124:10-16.

35. Jin WB, Xu Y, Yu XW. Formation lipase cross-linked enzyme aggregates on octyl-modified mesocellular foams with oxidized sodium alginate. Colloids Surf B Biointerfaces. 2019;184:110501.

36. Seddigi ZS, Malik MS, Ahmed SA, Babalghith AO, Kamal A. Lipases in asymmetric transformations: recent advances in classical kinetic resolution and lipase-metal combinations for dynamic processes. Coord Chem Rev. 2017;348:54-70.

37. Ferreira MM, de Oliveira GF, Basso RC, Mendes AA, Hirata DB. Optimization of free fatty acid production by enzymatic hydrolysis of vegetable oils using a non-commercial lipase from Geotrichum candidum. Biopro and Biosys E. 2019;42:1647-1659.

38. Rehman S, Bhatti HN, Bilal M, Asgher M. Cross-linked enzyme aggregates (CLEAs) of Pencilluim notatum lipase enzyme with improved activity, stability and reusability characteristics. Int J Biol Macromol. 2016;91:1161-1169.

39. Yamamoto K, Fujiwara N. The hydrolysis of castor oil using a lipase from Pseudomonas sp. f-B-24: positional and substrate specificity of the enzyme and optimum reaction conditions. Biosci, Biotech, and Biochemistry. 2014;59:1262-1266.

\section{Figures}



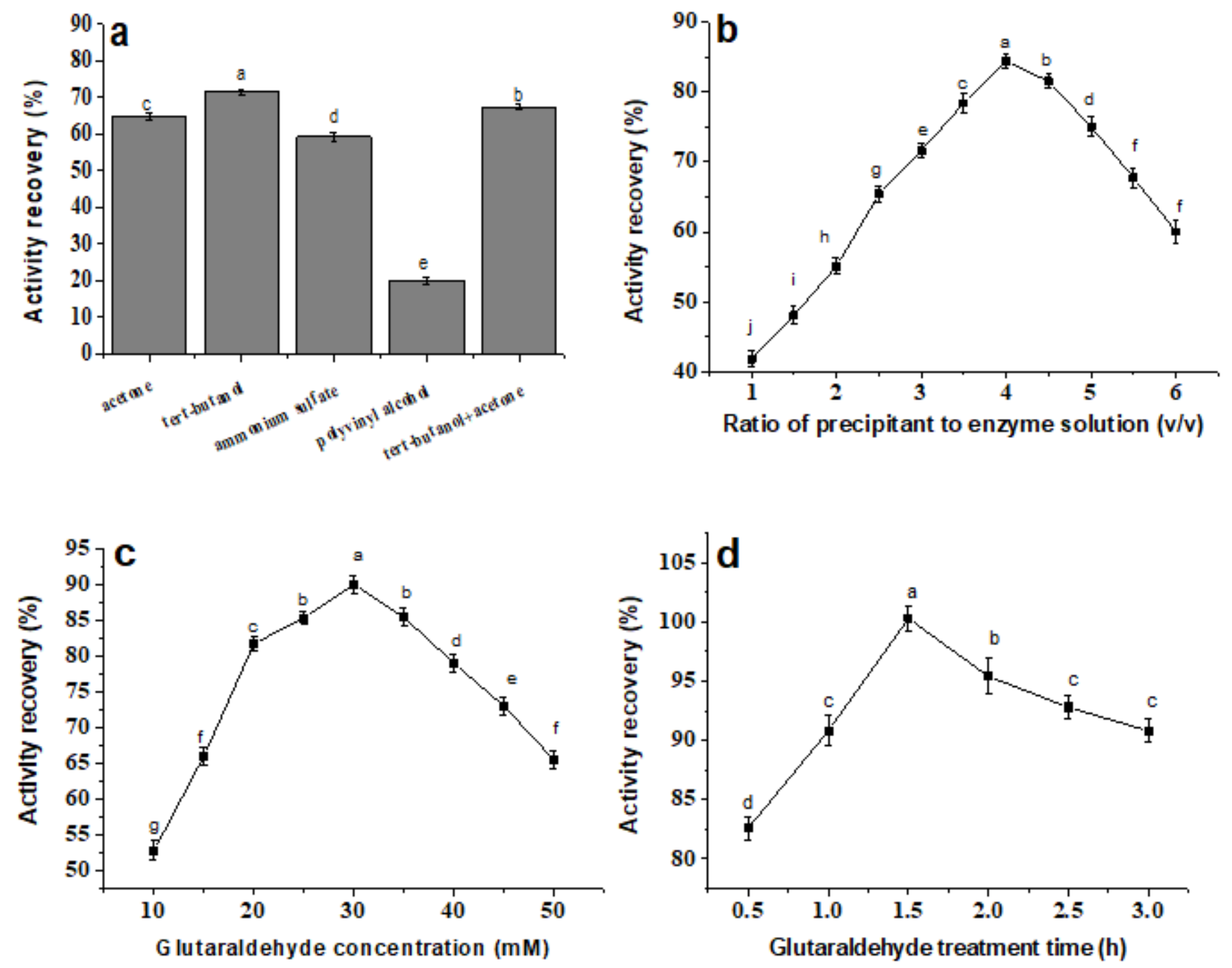

Figure 1

Effect of different parameters of CLEAs strategy on activity of purified EXANL1. a Precipitant types. $b$ Ratio of precipitant to enzyme solution. c Glutaraldehyde concentration. d Glutaraldehyde treatment time. Means with dissimilar lower case letters $(a-j)$ indicate significant differences between groups $(P<0.05)$. 

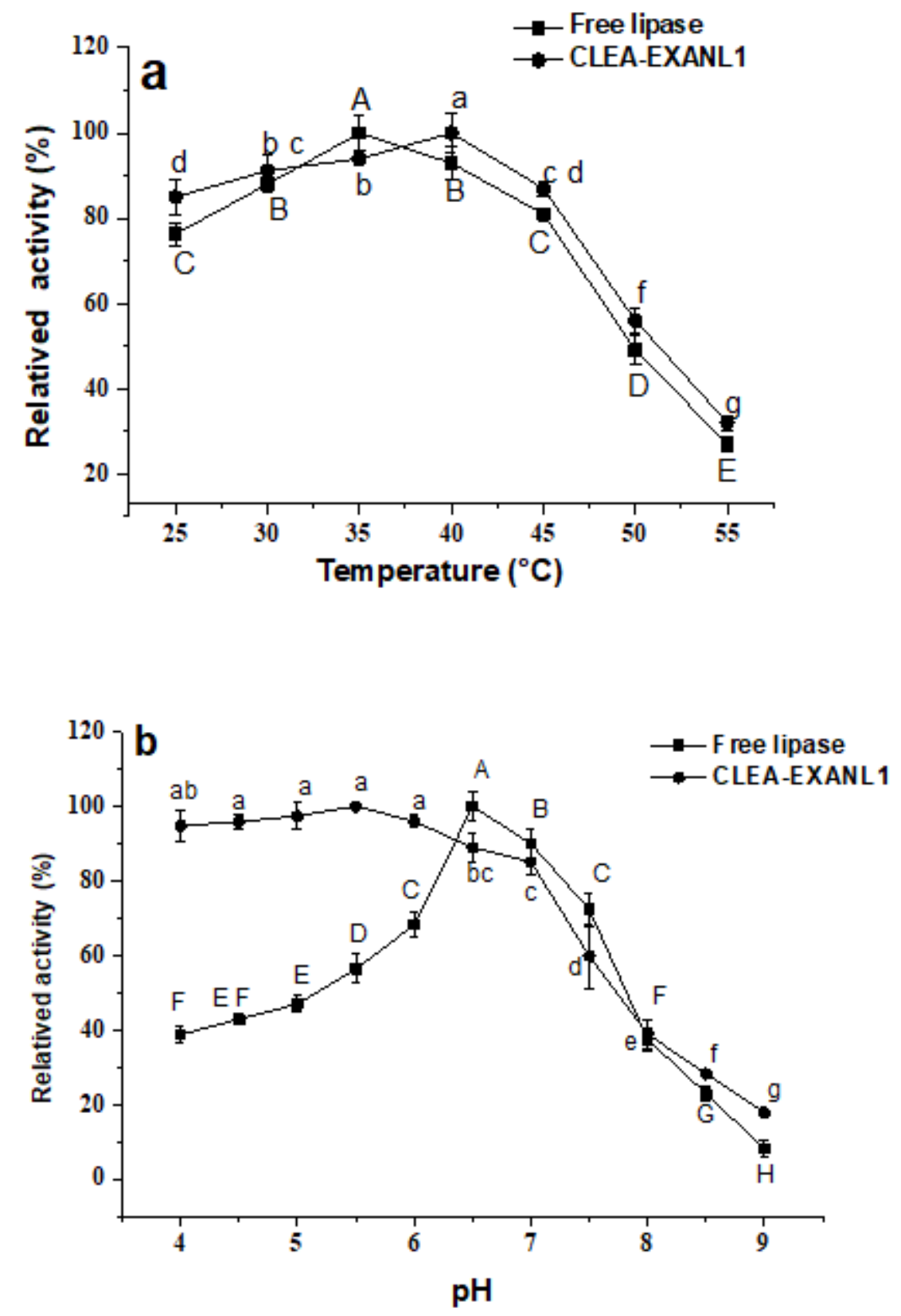

Figure 2

Optimal temperature a and $\mathrm{pH} b$ curves of free lipase and CLEA-EXANL1. Means with dissimilar lowercase letters $(a-g, A-G)$ indicate significant differences among the relative activity of CLEA-EXANL1 with different temperatures and $\mathrm{pH}$ values $(\mathrm{P}<0.05)$. 

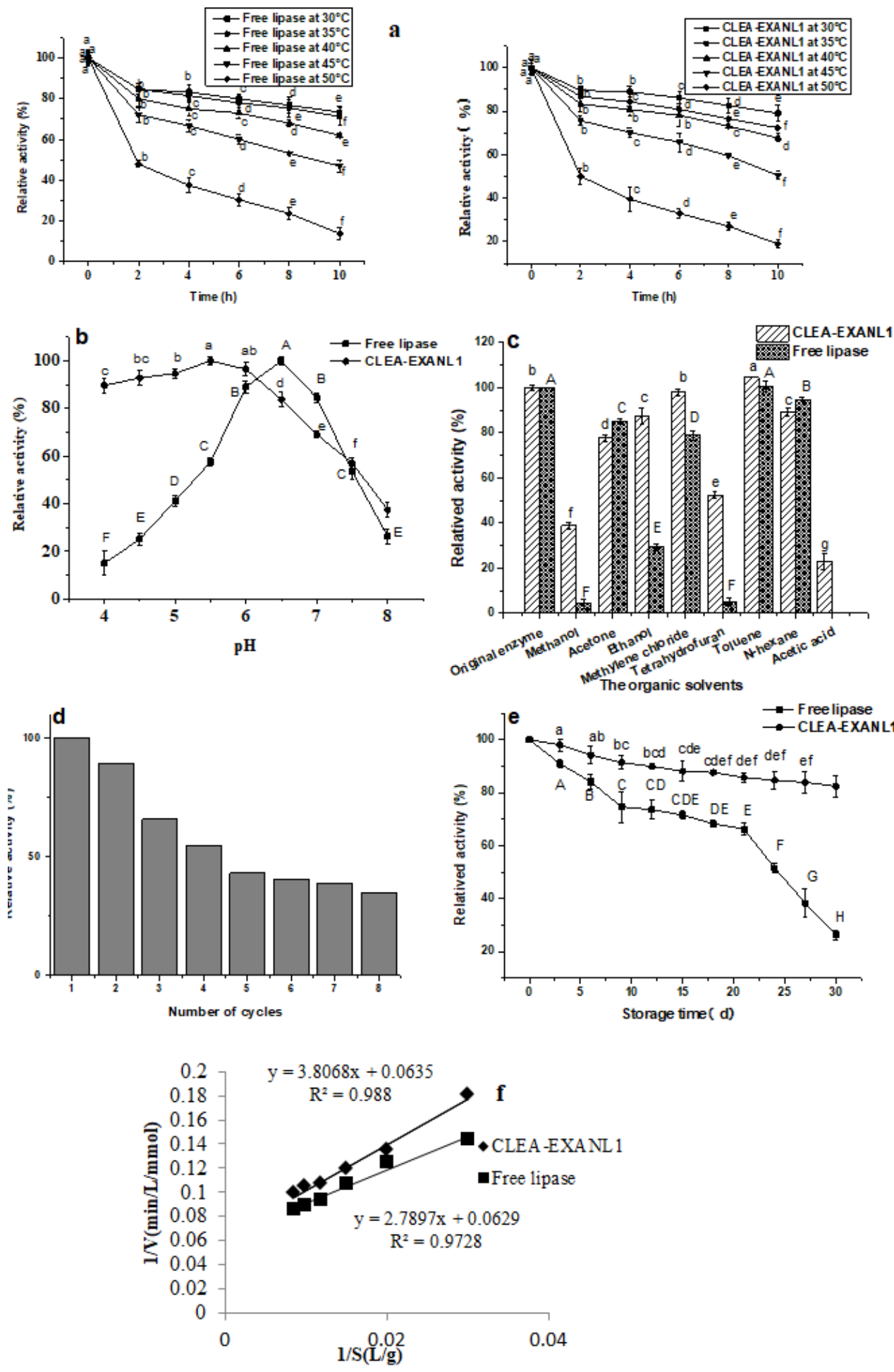

\section{Figure 3}

Stability analysis of free lipase and CLEA-EXANL1. a Temperature stability. b pH stability. c Organic solvent stability. d Reusability. e Storage stability. $f$ Kinetic. Means with dissimilar lower case letters (a-g, $A-H)$ indicate significant differences between groups $(P<0.05)$. 


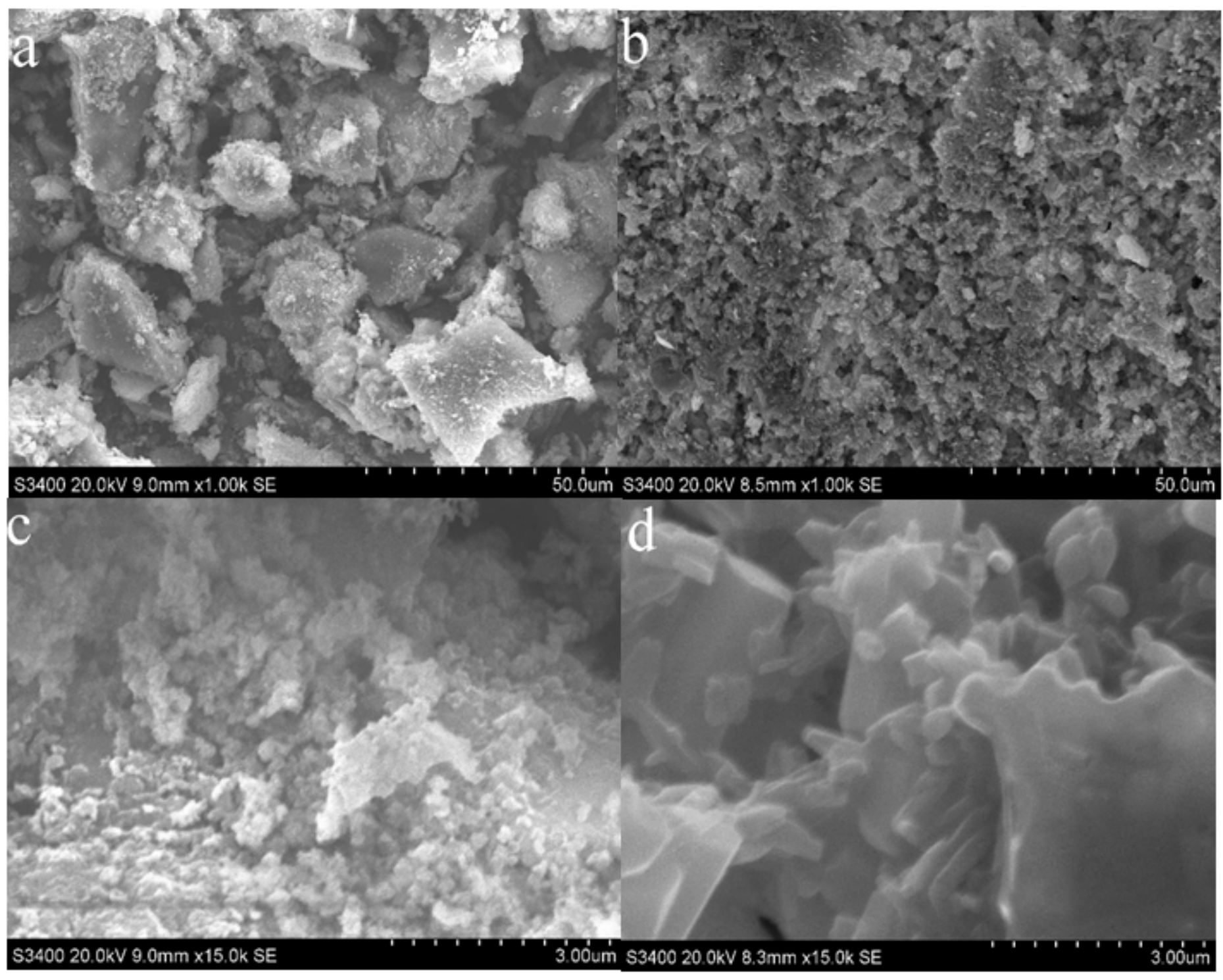

\section{Figure 4}

Scanning electron microscope images of free lipase and CLEAs-EXANL1. a Scanning electron microscope image of free EXANL1 under 1000× magnification. b Scanning electron microscope image of CLEAsEXANL1 under 1000x magnification. c Scanning electron microscope image of free EXANL1 under 15000x magnification. $d$ Scanning electron microscope image of CLEAs-EXANL1 under 15000x magnification. 

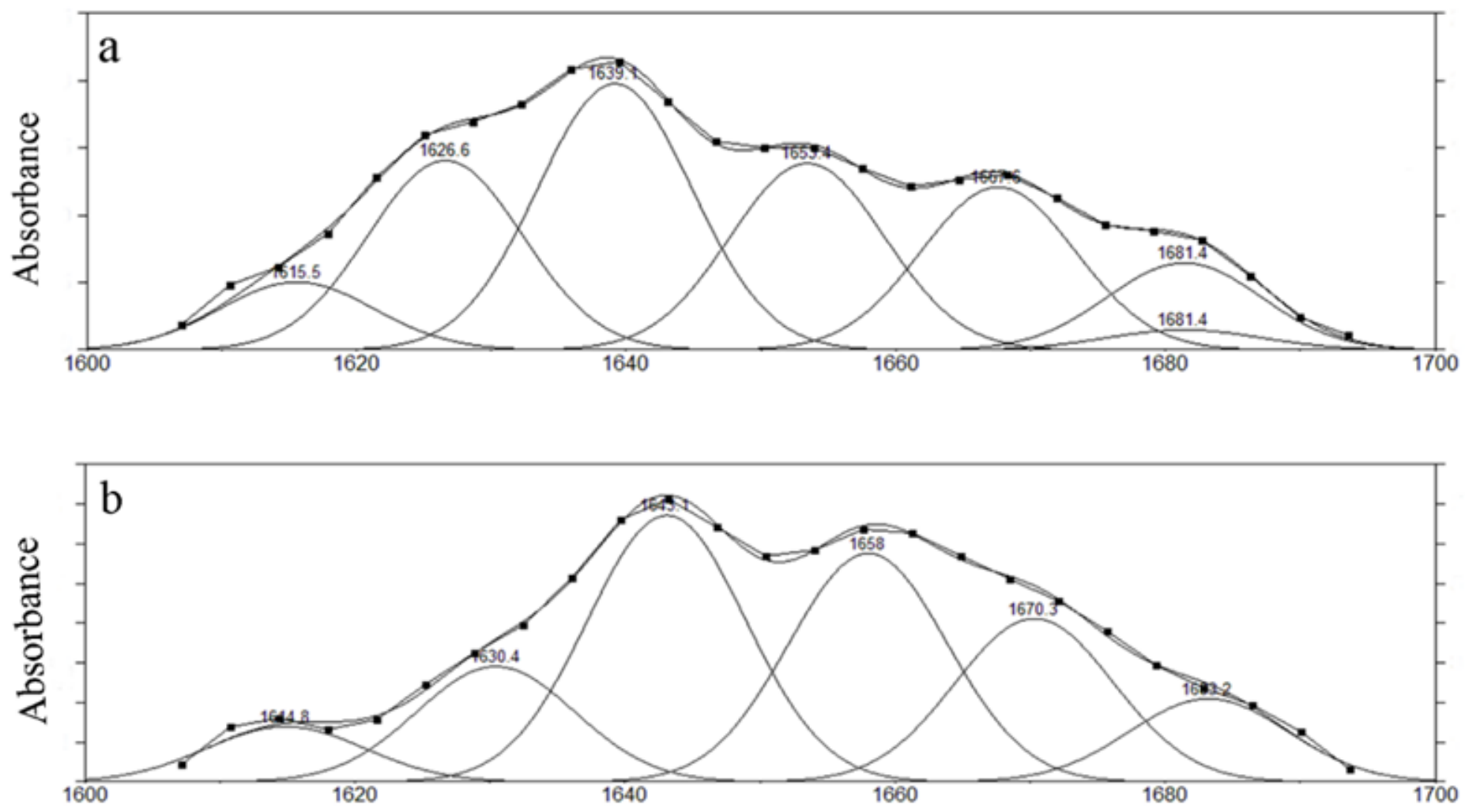

Figure 5

Secondary structural alteration analysis of a free lipase and b CLEA-EXANL1. The amide I spectrum with a wavelength range of $1600-1700 \mathrm{~cm}-1$ was selected for baseline correction, and the Peakfit 4.12 software was used for peak segmentation fitting to obtain six subpeaks. 
Triglyceride

0leic acid

\section{1, 3-diglyceride}

l, 2-diglyceride

Monoglyceride
(1) (2)
(3)
(4)
(5)
(6)

\section{Figure 6}

Thin layer chromatography analysis of hydrolysis reaction products (1) pure triolein (2) $65 \%$ triolein (3) 1,3 diglyceride standard (4) PPL hydrolysis reaction (5) free EXANL1 hydrolysis reaction (6) CLEAEXANL1 hydrolysis reaction. Reaction condition: $0.1 \mathrm{~mL}$ of triolein, $1 \mathrm{~mL}$ of enzyme incubated at $30{ }^{\circ} \mathrm{C}$ for $15 \mathrm{~min}$ at $180 \mathrm{rpm}$. 